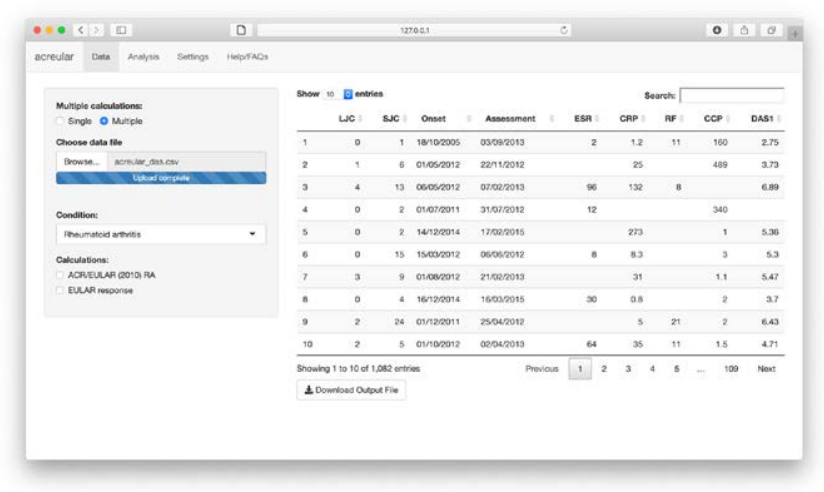

Figure 1. The Data tab following the upload of data. Criteria are calculated by the selecting the appropriate checkbox.

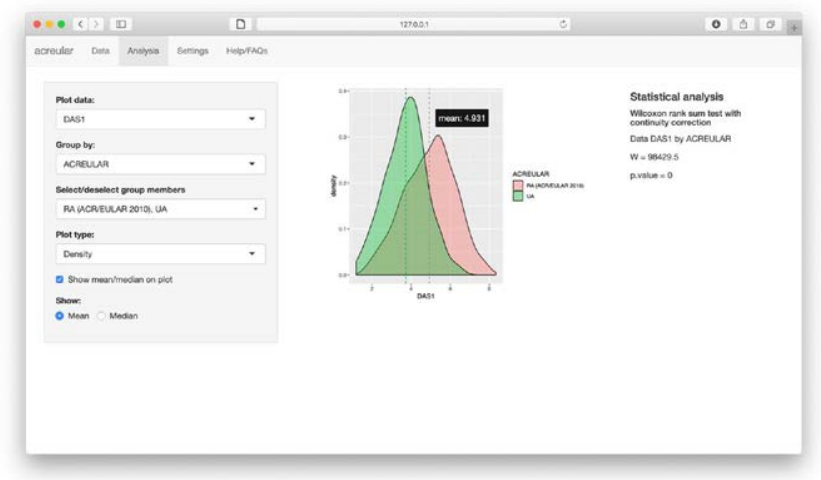

Figure 2. A density plot of DAS28 scores grouped by ACR/EULAR 2010 RA classification. Statistical analysis has been performed and shows a significant difference in DAS28 score between the two groups.

Conclusion: The acreular R package facilitates the easy calculation of ACR/ EULAR RA related disease measures for whole patient cohorts. Calculations can be performed either from within $\mathrm{R}$ or by using the accompanying web application, which also enables the graphical visualisation of data and the calculation of comparative statistics. We plan to further develop the package by adding additional RA related criteria and by adding ACR/EULAR related measures for other rheumatic disorders.

Disclosure of Interests: Fraser Morton: None declared, Jagtar Nijjar Shareholder of: GlaxoSmithKline plc, Consultant of: Janssen Pharmaceuticals UK, Employee of: GlaxoSmithKline plc, Paid instructor for: Janssen Pharmaceuticals UK, Speakers bureau: Janssen Pharmaceuticals UK, AbbVie, Carl Goodyear: None declared, Duncan Porter: None declared

DOI: 10.1136/annrheumdis-2020-eular.2326

\section{AB0211 DIFFERENTIAL INFLUENCE OF CDAI COMPONENTS BASED ON DISEASE STATE IN RHEUMATOID ARTHRITIS PATIENTS: REAL-WORLD RESULTS FROM THE ONTARIO BEST PRACTICES RESEARCH INITIATIVE (OBRI)}

E. Keystone ${ }^{1}$, M. Movahedi ${ }^{2,3}$, A. Cesta ${ }^{2}$, C. Bombardier ${ }^{1,2,4}$, J. Sampalis ${ }^{5}$, E. Rampakakis ${ }^{5}$ on behalf of OBRI investigators. ${ }^{1}$ Division of Rheumatology, Mount Sinai Hospital, Toronto, Canada; ${ }^{2}$ Toronto General Hospital Research Institute, University Health Network, Toronto, Canada; ${ }^{3}$ Institute of Health Policy, Management and Evaluation, University of Toronto, Toronto, Canada; ${ }^{4}$ Department of Medicine (DMO) and Institute of Health Policy, Management, and Evaluation (IHPME), Toronto, Canada, Toronto, Canada; ${ }^{5}$ JSS Medical Research, St-Laurent, Canada

Background: Treat-to-target recommendations for rheumatoid arthritis (RA) dictate that remission or low disease activity should be aimed. Although numerous composite indices are available, the clinical disease activity index (CDAl) is commonly used in routine clinical care due to its simplicity and non-reliance on acute phase reactants.
Objectives: The purpose of this analysis was to evaluate the CDAl properties both cross-sectionally and longitudinally in a cohort of RA patients followed in Canadian routine care.

Methods: RA patients enrolled in the Ontario Best Practices Research Initiative (OBRI), with available follow-up for $\geq 6$ months and data on CDAl, disease activity score based on 28 joints (DAS28), health assessment questionnaire (HAQ), and $A C R / E U L A R$ Boolean remission were included. For both the CDAI score and its change from baseline to 6 months, construct validity was assessed with principal component analysis, internal consistency with the Cronbach's alpha coefficient (a), correlational validity with the Spearman's rho coefficient, agreement in disease state classification with percent concordant pairs and the kappa statistic. Stratified analysis by presence of CDAl low disease activity (LDA) or remission was performed.

Results: 1,582 patients met the inclusion criteria. Principal component analysis showed that CDAl could be reduced to a single component when CDAI is $>10$ with SJC28 accounting for most variance in score and patient global assessment (PtGA) the least; whereas, when CDAl is $\leq 10$, two distinct components were identified, the first comprising PtGA and physician global assessment (PhGA) and the second SJC28 and TJC28. In terms of internal consistency, high levels were observed for both CDAl at baseline $(a=0.83)$ and its change from baseline to 6 months ( $a=0.81$ ); however, the consistency between CDAl components was very low when CDAl is $\leq 10(a=0.23)$.

Overall, a strong positive correlation was observed between CDAI and DAS28 (rho $=0.86)$ and their changes $(r h o=0.87)$ while its correlation with $\mathrm{HAQ}$ was weak. When stratifying by CDAI levels, the correlation of CDAI with DAS28 was moderate when CDAl is $\leq 10$ and very weak when CDAl is $\leq 2.8$. Similarly, agreement in the classification of LDA between CDAI and DAS28 or HAQ was fair to moderate, and agreement in classification of remission was poor to fair.

Conclusion: CDAI and DAS28 correlate well when disease activity is moderate or high and poorly in LDA or remission. PtGA had a stronger influence on CDAl at LDA or remission state compared to moderate or high disease state. Thus, careful interpretation of PtGA is necessary particularly in patients who are identified as CDAl non-remitters.

Disclosure of Interests: Edward Keystone Grant/research support from: AbbVie, Amgen, Bristol-Myers Squibb, F. Hoffmann-La Roche Inc, Gilead, Janssen Inc, Lilly Pharmaceuticals, Pfizer Pharmaceuticals, Sanofi-Aventis, Consultant of: AbbVie, Amgen, AstraZeneca Pharma, Biotest, Bristol-Myers Squibb Company, Celltrion, Crescendo Bioscience, F. Hoffmann-La Roche Inc, Genentech Inc, Gilead, Janssen Inc, Lilly

Pharmaceuticals, Merck, Pfizer Pharmaceuticals, Sandoz, UCB., Speakers bureau: Amgen, AbbVie, Bristol-Myers Squibb Canada, F. Hoffmann-La Roche Inc., Janssen Inc., Merck, Pfizer Pharmaceuticals, Sanofi Genzyme, UCB, Mohammad Movahedi Consultant of: Allergan, Angela Cesta: None declared, Claire Bombardier Grant/research support from: Dr Bombardier reports sources of funding for Ontario Best Practice Research Initiative Research grants from Abbvie, Janssen, Amgen, Medexus, Merck, Pfizer, and Novartis outside of the submitted work. Consulting Agreements: Abbvie, Covance, Janssen, Merck, Pfizer, Sanofi and Novartis outside of the submitted work. Advisory Board Membership: Hospira, Sandoz, Merck, Pfizer and Novartis outside of the submitted work., John Sampalis: None declared, Emmanouil Rampakakis: None declared DOI: 10.1136/annrheumdis-2020-eular.3913

\section{AB0212 12 FLARE RISK AFTER DISCONTINUING LONG-TERM METHOTREXATE TREATMENT IN PATIENTS HAVING RHEUMATOID ARTHRITIS WITH LOW DISEASE ACTIVITY}

S. H. Nam ${ }^{1}$, J. S. Lee ${ }^{1}$, S. J. Choi', W. J. Seo ${ }^{2}$, J. S. Oh ${ }^{3}$, S. Hong ${ }^{1}$, Y. G. Kim¹, C. K. Lee ${ }^{1}$, B. Yoo ${ }^{1}{ }^{1}$ University of Ulsan College of Medicine, Asan Medical Center, Division of Rheumatology, Department of Internal Medicine, Seoul, Korea, Rep. of (South Korea); ${ }^{2}$ Veterans Health Service Medical Center, Department of Internal Medicine, Seoul, Korea, Rep. of (South Korea); ${ }^{3}$ Asan Medical Center, Department of Biomedical Informatics, Seoul, Korea, Rep. of (South Korea)

Background: Several recent studies have reported that MTX could be discontinued in patients with low disease activity who are taking biologic DMARDs or tofacitinib. However, there are limited studies on whether MTX could be discontinued in patients with low disease activity who have taken MTX for a long term. Objectives: We investigated the disease flare rate in patients with rheumatoid arthritis (RA) who achieved low disease activity following long-term methotrexate (MTX) treatment and the factors related to flare.

Methods: This retrospective longitudinal cohort study included patients with RA and low disease activity who were exposed to MTX for $>10$ years. Disease flare was defined as an increase in DAS28 of $>1.2$ within 6 months of discontinuation of MTX. Logistic regression analysis was performed to identify the factors associated with flare. 